\title{
Excellent Smart Growth Metric for Cities
}

\author{
Haoxin Tian \\ School of North China Electric Power University, Baoding, Hebei, China \\ 768585058@qq.com
}

\begin{abstract}
Smart growth is an approach to development that encourages a mix of building types and uses, diverse housing and transportation options, development within existing neighborhoods, and community engagement. In this paper, a metric is defined to measure the success of smart growth of a city. By arranging the main indicators into different levels based on their relation to smart growth index and then through Delphi method, we calculate the coefficients of these indicators. At last, we explain the meaning of the indicators and illustrate our reasons for the metric.
\end{abstract}

Keywords: Smart Growth, metric, Delphi method.

\section{Introduction}

Smart growth is an urban planning theory that originated in 1990's as a means to curb continued urban sprawl and reduce the loss of farmland surrounding urban centers. Since the 1990s, many urban areas have encouraged the development of planned communities in which people can live, shop, work, go to school, worship, and recreate without having to travel great distances by automobile, a lot of people have benefit from this method.

When communities choose smart growth strategies, they can create new neighborhoods and maintain existing ones that are attractive, convenient, safe, and healthy. They can foster design that encourages social, civic, and physical activity. They can protect the environment while simulating economic growth.

When communities do this kind of planning, they preserve the best of their past while creating a bright future for generations to come ${ }^{[2]}$.

\section{The establishment of metric for the Smart Growth}

\subsection{Evaluation System}

In order to establish the system for evaluating the level of Smart Growth of a city, we can regard the external indicator as a Key Performance Indicator (KPI), and the size of index reflects the level of urban development. As Figure 1, environment, living, transportation, culture and economy should be included in our comprehensive consideration.

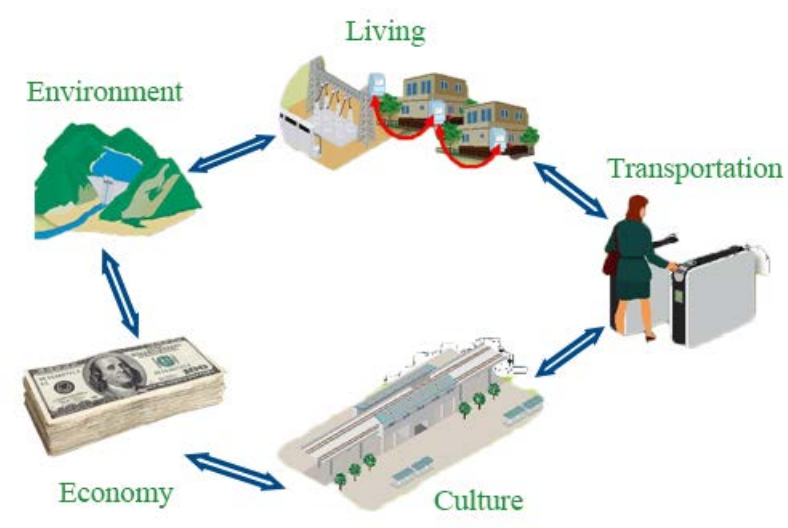

Figure 1. The Smart Growth system

By taking the direct goals and the evaluation criteria of different departments, experts then can build a multilevel index evaluation method. The evaluation indicators can be divided into 3 levels.

The first level is the main indicator we do our evaluation, that's Smart Growth coefficient; the indicators of the second level are intensity of urban land use growth, efficiency of urban land use growth, urban livable level and sustainable development. 
In order to build a general evaluation index, we have to integrate the internal relations between different indicators. For different urban areas, there are differences in population and scale, so it's not comparable in direct comparison. To avoid the problem, we adopt the method of ratio definition. The third level indicators and their belonging are shown in Figure 2.

\begin{tabular}{lll} 
The Second Level & \multicolumn{1}{c}{ The Third Level } \\
Intensity of urbanland & Erban population expansion coefficient \\
use growth & Economic expansion coefficient \\
Efficiency of urbanland & Land average output \\
use growth & Land average financial revenue \\
& Land average employment \\
Urban livable level & Road area per capita \\
& Gumber of buses per capita \\
& Medical bed per capital \\
Sustainable development & Public books per capital \\
& Erban population expansion coefficient \\
& Population density
\end{tabular}

Figure 2. Indicators in two levels

Then we need quantify the indicators in the second level and the third. We adopt internationally popular Delphi method to determine the relationship between the indicators at the same time level ${ }^{[5]}$. Based on the comprehensive weighting, we can get the Smart Growth coefficient.

Based on the Delphi method, we combine the results of some experts ${ }^{[5]}$ skilled in city planning and land policy. Using the following formula we can calculate the weight of each indicator.

$$
W=\frac{\sum_{j=1}^{n} E_{i j}}{n}
$$

W- - The weight of indicators;

$E_{i j}$ - The score expert $j$ gives the indicator $i$;

$n$ - - The number of experts

Finally we get the weight of each indicator as TABLE 1.

TABLE 1. Weights of indicators

\begin{tabular}{|c|c|c|c|}
\hline level & weight & level & weight \\
\hline \multirow{3}{*}{$\begin{array}{l}\text { Intensity of } \\
\text { urban land } \\
\text { use growth }\end{array}$} & \multirow{3}{*}{0.14} & $\begin{array}{l}\text { Urban population expansion } \\
\text { coefficient }\end{array}$ & 0.17 \\
\hline & & $\begin{array}{l}\text { Economic expansion } \\
\text { coefficient }\end{array}$ & 0.32 \\
\hline & & Population density & 0.51 \\
\hline \multirow{4}{*}{$\begin{array}{l}\text { Efficiency of } \\
\text { urban land } \\
\text { use growth }\end{array}$} & \multirow{4}{*}{0.24} & Land average output & 0.14 \\
\hline & & $\begin{array}{l}\text { Land average financial } \\
\text { revenue }\end{array}$ & 0.32 \\
\hline & & Land average employment & 0.54 \\
\hline & & Road area per capita & 0.1 \\
\hline \multirow{4}{*}{$\begin{array}{l}\text { Urban } \\
\text { livable level }\end{array}$} & \multirow{4}{*}{0.41} & Number of buses per capita & 0.23 \\
\hline & & Green coverage ratio & 0.29 \\
\hline & & Medical bed per capital & 0.18 \\
\hline & & Public books per capital & 0.2 \\
\hline \multirow{4}{*}{$\begin{array}{c}\text { Sustainable } \\
\text { development }\end{array}$} & \multirow{4}{*}{0.21} & Utilization of land resources & 0.24 \\
\hline & & $\begin{array}{l}\text { Energy consumption } \\
\text { elasticity coefficient }\end{array}$ & 0.36 \\
\hline & & $\begin{array}{l}\text { Elasticity coefficient of } \\
\text { industrial output value and } \\
\text { land use }\end{array}$ & 0.19 \\
\hline & & $\begin{array}{l}\text { Non construction land } \\
\text { proportion }\end{array}$ & 0.21 \\
\hline
\end{tabular}


What is worth our attention is that the relationship between indicators and the results. Urban population expansion coefficient and Economic expansion coefficient are contrary indicators to Smart Growth. And Utilization of land resources and Energy consumption elasticity coefficient are also in the same trend, while the others are in the opposite side. This point is quite important for our analysis later.

\subsection{Meaning of index}

Here we explain the meaning of index in TABLE 1 for our further discussion.

- Intensity of urban land use growth

The growth intensity is dynamic, so it's no suitable to select static indicators. We choose the indicators defined by the ratio, so it becomes comparable among different cities.

1. Urban population expansion coefficient equals growth rate of urban land use divided by urban population growth rate, it reflects the situation that the urban land use is changed with the growth of population.

2. Economic expansion coefficient equals growth rate of urban land use divided by economic growth, it helps to measure the growth of urban land use.

3. Population density equals to population divided by urban land use. It can represent the development intensity of urban construction land.

- Efficiency of urban land use growth

1. Land average output equals urban GDP divided by urban land use, it can measure the effectiveness of urban construction land use.

2. Land average financial revenue equals financial revenue divided by urban land use, the higher the total economic output per unit of land, the better growth efficiency.

3. Land average employment equals the number of employment divided by urban land use, the rate of employment is an important factor to measure the quality the growth of city.

- Urban livable level

The urban livable level refers to promotion of urban service facilities with the growth of land use.

1. Road area per capita equals road area divided by population, it determines the efficiency of production and life.

2. Number of buses per capita equals the number of buses divided by population, it reflects whether the growth of city is energy saving.

3. Green coverage ratio equals green coverage area divided by urban built-up area, it can measure the quality of construction.

4. Medical bed per capital equals the number medical bed divided by population.

5. Public books per capital equals the number of public books divided by population, medical care and cultural service reflect the degree of harmonious development.

- Sustainable development

Sustainable development principle is the important component of Smart Growth.

1. Utilization of land resources reflects the quantitative index of land use degree.

2. Energy consumption elasticity coefficient is the index reflecting the relationship between the growth rate of energy consumption and the growth rate of national economy.

3. Elasticity coefficient of industrial output value and land use, it equals industrial output value divided by urban construction land area.

4. Non construction land proportion refers to the proportion of non construction area.

\subsection{The reasons for metric}

So as to reflect the essence of Smart Growth as accurate as possible, except for the ten principles of it, we also obey the following principles in the process of designing and choosing our evaluating indicators:

\section{a) Science}

The evaluating indicators we choose must have connotation of science. And for its applicability, every indicator has to reflect the inner relationship between evaluation criterion and the growth of a city. Also, the actual situation of any region should be taken into account.

b) Comprehensiveness

The evaluating indicators should reflect the level of Smart Growth from many aspects not the single side. Smart Growth accomplish the urban overall planning that keeps the balance of land use, economic benefits, managements and ecology under the premise of sustainable development. So the indicators must include the above factors.

c) Feasibility 
The indicators should be in the range of the data statistics and can be conveniently fund out, and the geography, goal, the present situation should be considered. And the most important is keeping the reliability and authenticity of the data.

d) Sustainability

The implementation of any plan is not accomplished overnight, it need to go through a certain stage of development. So the indicators need to reflect the sustainability on time, economy, society, and ecology.

\section{Conclusions and Future Work}

In this paper, a metric is presented to measure the success of smart growth of a city. And we have argued that it has strong versatility and scalability.

While the development of a city is highly dynamic, the compiling method of urban master planning must adapt to the increasing uncertainty of city development prospect accompanied by the increasing of uncertain factors in urban growth. In the future, how to face a flood of opportunities and challenges in the process of the urban development is the main question that needs further discussion.

\section{References}

[1] Smart Growth: Improving lives by improving communities. https://smartgrowthamerica.org/

[2] EPA, "This is Smart Growth.” 2016 https://www.epa.gov/smartgrowth/smart-growth-publication

[3] Galster G, Hanson R, Ratcliffe M R, et al. Wrestling sprawl to the ground: defining and measuring an elusive concept[J]. Housing policy debate, 2001, 12(4): 681-717.

[4] Liu Donghua. Research on Urban Smart Growth for low consumption of land - take Shanghai for example[D]. Economy and Management College of Tongji University,2007.

[5] Cheng Maoji. Research on the evaluation and optimization of urban growth in Nanjing based on Smart Growth[D]. Nanjing Normal University,2012.

[6] World urbanization prospects, highlights, 2014. The United Nations.

[7] Anhui statistical yearbook, Retrieved from: http://www.ahtjj.gov.cn/tjj/web/index.jsp

[8] Kwara Database, http://www.kwarastate.gov.ng/

[9] BEA Database, https://www.bea.gov/

[10] Ren Kui, Zhou Shenglu, Zhang Hongfu, Optimal allocation of regional land use structure based on smart growth concept[J]. Resource Science, 2008,6(30):912-9 